\title{
A STUDY OF THE POTENTIAL THERAPEUTIC EFFECT OF GINGER (ZINGIBER OFFICINALE) LOADED NANOPARTICLES ON MURINE SCHISTOSOMIASIS MANSONI
}

\author{
By \\ MONA MOHAMMED EL-DERBAWY ${ }^{1^{*}}$, WALAA ABD EL MONEIM SOLIMAN EL \\ KHOLY ${ }^{1}$, IBRAHIM RABIA BAIUOMY ${ }^{2}$ and HALA SAID SALEM ${ }^{1}$ \\ Department of Medical Parasitology, Faculty of Medicine (Girls), Al-Azhar University ${ }^{1}$, \\ Nasr City and Department of Immunology and Parasitology, Theodor Bilharz \\ Research Institute ${ }^{2}$, Imbaba P.O. Box 30, Giza, Egypt \\ ( ${ }^{\star}$ Correspondence: dr_monagyobs@yahoo.com)
}

\begin{abstract}
Chemotherapy is the most widely advocated method of antischistosomal control. Repeated chemotherapy has resulted in the emergence of drug-resistant schistosome strains. In the last few years, such resistance has drawn the attention to alternative drugs especially from natural sources (ginger). Nanoparticles have received special attention because they act as potent drug delivery systems. This study evaluated the antischistosomal effect of ginger extract loaded on chitosan nanoparticles on Schistosoma mansoni experimentally infected mice. The present study was conducted on sixty eight female $\mathrm{BALB} / \mathrm{C}$ mice. Mice were exposed to $80 \pm 10$ cercariae per mouse and divided into 3 main groups;(G1) negative control, (G2) positive control, G3) infected /treated, either by ginger extract (G3a), chitosan nanoparticles (G3b), praziquantel (G3c) or ginger extract loaded on chitosan nanoparticles (G3d). All groups were evaluated by parasitological and biochemical parameters. The results showed that worm burden and the egg density in liver were significantly reduced with $\mathrm{P}$ value $<0.001$ in G3d. The alanine aminotransferase (ALT) and aspartate aminotransferase (AST) activities were significantly decreased in group G3d with $p$ value $<0.001$ which indicated recovery of the liver tissue.
\end{abstract}

Key words: Ginger, Praziquantel, Chitosan nanoparticles, Schistosoma mansoni

\section{Introduction}

Schistosomiasis control strategy is based on the treatment of infected patients with selected drug as praziquantel (Mostafa et al, 2011). For centuries, ginger has been used in traditional medicine for respiratory disorders, stroke, hypercholesterolaemia, and schistosomiasis (Ali et al, 2008; Islam et al, 2008). It has antibacterial, antifungal, antioxidant, and anti-inflammatory effects and it increases the phagocytic activity and disease resistance against pathogens (Imtiyaz et al, 2013; El-Sayed et al, 2015). Unfortunately, the long term worldwide application of praziquantel coupled with the discovery of praziquantel-tolerant schistosome has triggered concern over the development of drug-resistant Schistosoma strains (Appiah et al, 2000).

Few investigations were done upon the antihelminthic activity of ginger and its constituents and showed that both crude powder and aqueous extract of dried ginger showed anti-helminthic activity in sheep (Iqbal et al, 2006). The nanotechnology embraces prom- ise for medication and nutrition, as materials at the nanometer dimension exhibit novel properties different from those of isolated atoms and bulk material (Isaac et al, 2013).

Given the previous layout, the current work studied the anti-schistosomal effect of ginger extract loaded on chitosan nanoparticles on Schistosoma mansoni experimentally infected mice.

\section{Material and Methods}

Experimental design: The study was carried out on sixty eight female BALB/ C mice, 6-8 weeks old (18-20g),divided into 3 main groups;(G1) 8 mice uninfected untreated, (G2) 12 infected untreated mice, (G3) infected/treated groups subdivided into, (G3a) 12 mice treated by ginger extract, (G3b) 12 mice treated by chitosan nanoparticles, (G3c) 12 mice treated by praziquantel and (G3d) 12 mice treated by ginger extract loaded on chitosan nanoparticles.

Mice infection: Mice infected with $80 \pm 10$ $S$. mansoni cercaria via subcutaneous route (Peters and Warren, 1969). Mice and cercariae were purchased from the Schistosome 
Biological Supply Program Unit, Theodor Bilharz Research Institute (TBRI), Imbaba.

Treatment of mice: Aqueous extract of ginger was prepared by dissolving thirty gram of ginger powder in sixty $\mathrm{ml}$ of distilled water then it was squeezed out through piece of cloth. The extract was stored at$20^{\circ} \mathrm{C}$, and freshly prepared every three days. Aqueous ginger extract was orally administered $(500 \mathrm{mg} / \mathrm{kg} /$ day with an esophageal tube for five weeks starting from the $5^{\text {th }}$ week post-infection three days per week (Mo-

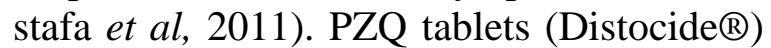
was supplied by Egyptian International Pharmaceutical Industries Company, EIPICO. It was given orally to mice in a dose of $500 \mathrm{mg}$ $/ \mathrm{kg}$ body weight for 2 consecutive days from $5^{\text {th }}$ week post-infection (Muchirah et al, 2012). Chitosan (with degree of deacetylation $85-93 \%$ ) and sodium tripolyphosphate (TPP) were purchased from Sigma Aldrich, St. Louis, USA. Chitosan nanoparticles were synthesized via the ionotropic gelation of the chitosan with TPP anions.

Parasitological studies: S. mansoni worms from the hepatic portal system and mesenteric veins of sacrificed mice were done by the perfusion technique (Pellegrino et al,
1977). Egg counting in hepatic tissues after scarification of mice, a piece of the liver tissues was stored at $-20^{\circ} \mathrm{C}$ for counting of the deposited eggs (Cheever, 1968).

Biochemical measurements: Activities of alanine aminotransferase (ALT) and aspartate aminotransferase (AST) in the liver homogenate were assayed according to the method (Bergmeyer et al, 1986) using Sigma Diagnostic kits (USA). Serum total protein concentrations (TP), documenting the extent of liver dysfunction, were determined calorimetrically using a Sigma Diagnostic kit (Sigma Chemical Co., St. Louis, MO) following the instructions provided by the manufacturer. Reduced glutathione (GSH) was measured (Schmidt and Schmidt, 1981). Lipid peroxidation was estimated by measuring liver thiobarbituric acid reactive substances (TBARS) as malon-dialdehyde (MDA), which was estimated (Ohkawa et al, 1979).

\section{Results}

In comparison to G2 (Tab. 1) showed mean total worm burden $25.75 \pm 3.15$, the mean total worm burden in G3a, G3b, G3c \& G3d were $(8.57 \pm 98 ; 6.13 \pm 2.59 ; 4.57 \pm 1.51 ; 1.75 \pm$ $1.04)$, respectively with significant difference (P-value $<0.001)$.

Table 1: Effect of different drugs on worm burden in groups:

\begin{tabular}{|c|c|c|}
\hline Groups & Mean \pm SD & P value \\
\hline G2 & $25.75 \pm 3.15$ & \\
\hline G3a & $8.57 \pm .98$ & $<0.001$ \\
\hline G3b & $6.13 \pm 2.59$ & $<0.001$ \\
\hline G3c & $4.57 \pm 1.51$ & $<0.001$ \\
\hline G3d & $1.75 \pm 1.04$ & $<0.001$ \\
\hline
\end{tabular}

Concerning oogram pattern (Tab. 2), in G2, immature egg was $62.79 \pm 6.66$ but, mature one was $34.53 \pm 6.54 \&$ dead egg was $2.69 \pm 1.22$. In G3a, immature egg was 71.79\pm 2.05 but, mature one was $26.71 \pm 2.31$ \& dead egg was $1.50 \pm 1.14$. In G3b, immature egg was $69.72 \pm 5.16$ but mature one was
$28.42 \pm 4.71 \&$ dead egg was $1.87 \pm 1.23$. In G3c, immature egg was $65.56 \pm 8.52$, but, mature egg was $23.87 \pm 6.36$ and dead egg was $10.57 \pm 4.87$. In G3d, immature egg was $56.83 \pm 6.81$ but mature egg was $31.44 \pm 4.67$ and dead egg was $12.99 \pm 1.63$, significant as compared to positive control $(\mathrm{P}<0.001)$.

Table 2: Oogram pattern in different study groups.

\begin{tabular}{|c|c|c|c|c|c|c|}
\hline & \multicolumn{2}{|c|}{ Immature eggs \% } & \multicolumn{2}{c|}{ Mature eggs\% } & \multicolumn{2}{c|}{ Dead eggs\% } \\
\hline Group & Mean \pm SD & P value & Mean \pm SD & P value & Mean \pm SD & P value \\
\hline G2 & $62.79 \pm 6.66$ & & $34.53 \pm 6.54$ & & $2.69 \pm 1.22$ & \\
\hline G3a & $71.79 \pm 2.05$ & $<0.006$ & $26.71 \pm 2.31$ & $<0.012$ & $1.50 \pm 1.14$ & $<0.074$ \\
\hline G3b & $69.72 \pm 5.16$ & $<0.035$ & $28.42 \pm 4.71$ & $<0.05$ & $1.87 \pm 1.23$ & $<0.20$ \\
\hline G3c & $65.56 \pm 8.52$ & $<0.49$ & $23.87 \pm 6.36$ & $<0.007$ & $10.57 \pm 4.87$ & $<0.005$ \\
\hline G3d & $56.83 \pm 6.81$ & $<0.098$ & $31.44 \pm 4.67$ & $<0.29$ & $12.99 \pm 1.63$ & $<0.001$ \\
\hline
\end{tabular}


Egg count per gram of liver or intestinal tissue compared to positive control (G2) where $\mathrm{t}$ mean hepatic and intestinal egg load/gm tissue were $(5876.13 \pm 1111.55$ \& $17584.38 \pm 1176.73)$ respectively, with a decrease in mean hepatic \& intestinal egg load in G3a $\quad(3885.43 \pm 802.24 \quad \& \quad 9523.71 \pm$ 701.97), G3b (5100.13 $\pm 646.11 \& 11957.00 \pm$ $754.12), \mathrm{G} 3 \mathrm{c}(2627.71 \pm 497.19 \& 3944.86 \pm$ $492.28)$ and in G3d $(2941.13 \pm 472.31 \&$ $11957.00 \pm 754.12$ ) respectively (Tab. 3).

Table 3: Egg count per gram of liver \& intestinal tissue

\begin{tabular}{|c|c|c|c|c|}
\hline Group & \multicolumn{2}{|l|}{ Intestine } & \multicolumn{2}{|l|}{ Liver } \\
\hline & Mean \pm SD & $\mathrm{P}$ value & Mean \pm SD & $\mathrm{P}$ value \\
\hline G2 & \multicolumn{2}{|l|}{$17584.38 \pm 1176.73$} & \multicolumn{2}{|c|}{$5876.13 \pm 1111.55$} \\
\hline G3a & $9523.71 \pm 701.97$ & $<0.001$ & $3885.43 \pm 802.24$ & $<0.002$ \\
\hline G3b & $11957.00 \pm 754.12$ & $<0.001$ & $5100.13 \pm 646.11$ & $<0.11$ \\
\hline G3c & $3944.86 \pm 492.28$ & $<0.001$ & $2627.71 \pm 497.19$ & $<0.001$ \\
\hline G3d & $4555.63 \pm 574.85$ & $<0.001$ & $2941.13 \pm 472.31$ & $<0.001$ \\
\hline
\end{tabular}

In G3a: compared to positive control there was a significant change in ALT, AST, TP, GSH \& MDA. In G3b: compared to positive control there was a significant change in ALT, AST, TP, GSH \& MDA. In G3c: compared to positive control there was a significant change in ALT, AST, GSH \& MDA but, TP changes were insignificant. In G3d: compared to positive control there was a highly significant change in ALT, AST, TP, GSH \& MDA (Tab. 4).

Table 4: ALT, AST, TP, GSH \& MDA measurements in different groups.

\begin{tabular}{|l|l|l|l|l|l|}
\hline Group & AST & ALT & TP & GSH & MDA \\
\hline G1 & $28.29 \pm 1.50$ & $23.43 \pm 2.57$ & $7.01 \pm .07$ & $3.87 \pm .11$ & $29.99 \pm .27$ \\
\hline G2 & $73.88 \pm 4.49$ & $66.63 \pm 3.70$ & $7.69 \pm .10$ & $1.83 \pm .10$ & $40.29 \pm .38$ \\
\hline G3a & $64.57 \pm 3 \mid<0.001$ & $61.29 \pm 1 .<0.05$ & $7.64 \pm .0 .4$ & $3.11 \pm . \mid<0.001$ & $37.14 \pm .1<0.001$ \\
\hline G3b & $52.25 \pm 2<0.001$ & $44.75 \pm 1<0.001$ & $7.18 \pm . \mid<0.001$ & $2.74 \pm . \mid<0.001$ & $39.79 \pm . \mid<0.05$ \\
\hline G3c & $57.86 \pm 1<0.001$ & $42.71 \pm . \mid<0.001$ & $7.14 \pm . \mid<0.001$ & $2.99 \pm$. & $38.09 \pm . \mid<0.001$ \\
\hline G3d & $45.13 \pm 3<0.001$ & $46.25 \pm 2<0.001$ & $6.84 \pm . \mid<0.001$ & $2.05 \pm . \mid<0.001$ & $33.44 \pm .<0.001$ \\
\hline
\end{tabular}

Statistical analysis: Data were expressed as $\mathrm{M} \pm \mathrm{SD}$. Differences between groups were determined using an ANOVA followed by the student-Newman-Keuls t-test. The level of significance was accepted with $\mathrm{p}$ value $<$ 0.05 .

\section{Discussion}

In the present study, the usage of the crude aqueous extract of ginger loaded on chitosan nanoparticles at a dose of $500 \mathrm{mg} / \mathrm{kg}$ body weight showed antischistosomal activity as indicated by reduction in worm recovery and egg density in the hepatic tissue of treated mice. Ginger was reported by various authors to have some degrees of anti-schistosomal effects through increasing the rates of schistosome worm reduction or reducing $S$. mansoni egg output and liver granuloma size (Al-Sharkawi et al, 2007; Mostafa et al, 2011). This agreed with anti-helmintic Lin $e t$ al. (2010a, b) of ginger against some nematode larvae whom used 6-gingerol, 10- shogaol, 10-gingerol, 6-shogaol and hexahydrocurcumin, a constituent isolated from ginger as larvicidal agents against Angiostrongylus cantonensis and Anisakis simplex larvae, respectively. They found that the constituents killed $A$. cantonensis and A. simplex larvae or reduced spontaneous movements in a time- and do-se-dependent way. Reduction in worm recovery and egg density in treated mice was considered as a potent evidence of effectiveness of anti-schistosomal drugs (Utzinger et al, 2002; Suleiman et al, 2004; Mati et al, 2010).

The decrease in levels of cytoplasmic enzymes AST, ALT \& TP contents in the liver of G3d, might reflect necrosis in hepatocytes with increased leakage of these enzymes to blood and replacement of normal liver tissue 
by granuloma lesions around entrapped schistosome eggs. Elevations of AST and ALT in sera of $S$. mansoni infected mice and patients with hepatosplenomegaly or decompensatation of liver cirrhosis (Fahim et al, 2000; Mahmoud et al, 2002). Awadalla et al. (1975), Hanna et al. (2003); Ahmed and Mostafa (2003); and Ahmed and Allam (2009) found a decrease of AST \& ALT contents in liver homogenate of $S$. mansoni infected mice. El-Badrawy et al. (1991) and Hanna and Fayez (1996) found increases in serum transaminases in $S$. mansoni infected mice that reflect increased leakage of cytoplasmic enzymes from liver cells to blood stream.

In the present study, treatment of $S$. mansoni infected mice with aqueous ginger extract loaded on chitosan nanoparticles produced a potential decrease of elevated liver peroxidation and increased liver function that reflect the antioxidant defense system represented by GSH. This agreed with Ahmed et al. $(2000 a, b)$ reported that feeding of ginger in diet $(1 \% \mathrm{w} / \mathrm{w})$ lowered lipid peroxidation by maintaining the activities of antioxidant enzymes-superoxide dismutase, catalase and glutathione peroxidase in experimentally induced oxidative stress in rats. Besides, Ahmed et al. (2008) reported that feeding of ginger attenuated lindane-induced lipid peroxidation in rats accompanied by modulation of oxygen free radical scavenging enzymes as well as reduced glutathione (GSH) and the GSH dependent enzymes glutathione peroxidase, glutathione reduct ase and glutathione-S-transferase.

Sakr (2007) showed that ginger exhibited potent free radicals scavenging activity as it reduced serum level of malndialdehyde and increased the catalytic activity of serum superoxide dismutase.

\section{Conclusion}

The present study showed that ginger loaded on chitosan nanoparticles have antischistosomal activities and decrease the produced oxidative damage of liver cells. Consequently, helps in liver tissue recovery and provides a basis for subsequent experimental and clinical trials.

\section{Acknowledgment}

The authors would like to Dr. Mona Abdel Daym Abd Rabbo, Department of Medical Parasitology, Faculty of Medicine (Girls), Al-Azhar University,

\section{References}

Ahmed, OM, Allam, G, 2009: The significance of vasoactive intestinal peptide in the treatment of Schistosoma mansoni-infected diabetic mice. Asian J. Anim. Vet. Adv. 4, 4:172-90.

Ahmed, OM, Mostafa, OMS, 2003: Experimental use of black seed oil against Schistosoma mansoni in albino mice. IV. Oxidative stress markers and some biochemical parameters in liver and kidney. J. Egypt. Ger. Soc. Zool. 41, A: 227-53.

Ahmed, RS, Seth, V, Banerjee, BD, 2000: Influence of dietary ginger (Zingiber officinales Rosc) on antioxidant defense system in rat: comparison with ascorbic acid. Indian J. Exp. Biol. 38, 6:604-6.

Ahmed, RS, Seth, V, Pasha, ST, Banerjee, BD, 2000: Influence of dietary ginger (Zingiber officinales Rosc) on oxidative stress induced by malathion in rats. Food Chem. Toxicol. 38, 5: 443-50.

Al-Sharkawi, IM, El-Shaikh, KA, Tabl, GA, Ali, JA, 2007: The effect of ginger on Schistosoma mansoni infected mice. Delta J. Sci. 31:110.

Ali, BH, Blunden, G, Tanira, MO, Nemmar, A, 2008: Some phytochemical, pharmacological and toxicological properties of ginger (Zingiber officinale Roscoe): A review of recent research. Food Chem. Toxicol. 46:409-20.

Appiah, AD, DeVlas, SJ, 2000: Interpreting low praziquantel cure rates of Schistosoma mansoni infections in Senegal. Trends Parasitol. 18:125-9.

Awadalla, HN, Sherif, AF, Shafel, AZ, Khalil, HA, Guirgis, FK, 1975: Enzyme lipids in homogenates of liver from mice infected with $S$. mansoni and from uninfected mice. Int. J. Parasitol. 5, 1:27-31.

Bergmeyer, HV, Herder, M, Rej, R, 1986: Approved recommendation on IFCC methods for the measurement of catalytical concentration of enzymes. Part 2- IFCC method for aspartate aminotransferase. J. Clin. Chem. Clin. Biochem. 24:497-9. 
Cheever, AW, 1968: Quantitative comparison of the intensity of Schistosoma mansoni infections in man and experimental animals. Trans. R. Soc. Trop. Med. Hyg, 63:781-95.

El-Badrawy, NM, Abdel-Hadi, AM, Voss, B, Metwally, AA, Ebeid, F, 1991: Effect of Praziquantel on the distribution of interstitial collagen type I and III and basement membrane collagen type IV and V in murine hepatic schistosomiasis. Trans. Roy. Soc. Trop. Med. Hyg. 85:752-5.

El-Sayed, NM, El-Saka, M, 2015: Anti-parasitic activity of Zingiber officinale (Ginger): A Brief Reciew. Aperito J. Bacteriol. Virol. Parasitol. 2, 1:112-9

Fahim, FA, Esmat, AY, Hassan GK, AbdelBary, A, 2000: Biochemical changes in patients with combined chronic schistosomiasis and viral hepatitis C infections. Dis. Mark.16, 3/4:111-6.

Hanna, LS, Fayez, V, 1996: Effect of inter-action of hepaticschistosomiasis mansoni \& an organophosphorus poisoning on some biochemical parameters in mice. J. Egypt. Ger. Soc. Zool. 19, A:195-220.

Hanna, LS, Medhat, AM, Abdel-Menem, HA, 2003: Biochemical changes after subchronic and chronic interaction of Schistosoma mansoni infection in Swiss Albino mice with two specific compounds. J. Egypt. Soc. Parasitol. 33, 1:24560.

Hirsch, C, Zouain, CS, Alves, JB Goes, AM, 1997: Induction of protective immunity and modulation of granulomatous hypersensitivity in mice using PIII, an anionic fraction of Schistosoma mansoni adult worm. Parasitology 115:218.

Imtiyaz, S, Rahman, K, Sultana, A, Tariq, M, Chaudhary, SS, 1997: Zingiber officinale Rosc: A traditional herb with medicinal properties. Tang. 3:21-6.

Iqbal, A, Farrukh, A, Zafar, M, 2006: Antioxidant and free radical scavenging properties of twelve traditionally used Indian Med. Plants. J. Biol. 30:177-83.

Islam, MS, Choi, H, 2008: Comparative effects of dietary ginger (Zingiber officinale) and garlic (Allium sativum) investigated in a type 2 diabetes model of rats. J. Med. Food 11:152-9.

Isaac, RSR, Sakthivel, G, Murthy, C, 2013: Green synthesis of gold and silver nanoparticles using Averrhoa bilimbi fruit extract. J. Nanotechnol. 13, doi.org/10/1155 / 2013/906592

Lin, RJ, Chen, CY, Chung, LY, Yen, CM, 2010a: Larvicidal activities of ginger (Zingiber officinale) against Angiostrongylus cantonensis. Acta Trop.115, 1/2:69-76.

Lin, RJ, Chen, CY, Lee, JD, Lu, CM, Chung, LY, et al, 2010b: Larvicidal constituents of Zingiber officinale (ginger) against Anisakis simplex. Plant Med.76, 16):1852-8.

Mahmoud, MR, El-Abhar, HS, Saleh, S, 2002: The effect of Nigella sativa oil against the liver damage induced by Schistosoma mansoni infection in mice. J. Ethnopharm. 70, 1:1-11.

Mati, VL, Freitas, RM, Melo AL, 2010: Effects of pentoxifylline during Schistosoma mansoni infection in Swiss mice: an analysis of worm burden, fecundity and liver histopathology. J, Helminthol. 29:1-7.

Mostafa, OM, Eid, RA, Adly, MA, 2011: Antischistosomal activitof ginger (Zingiber officina-

le) against Schistosoma mansoni ha-rbored in C57 mice. Parasitol. Res.109:395-403.

Muchirah, PN, Yole, D, Kutima, H, Waihenya, R, Kuria, KM, 2012: Determination of effective praziquantel dose in different mouse strains: $\mathrm{BALB} / \mathrm{c}$ and Swiss mice in treatment of Schistosoma mansoni. J. Clin. Immnunol. Immunopathol. Res. 4:12-21.

Ohkawa, H, Ohishi, N, Yagi, K, 1979: Assay for lipid peroxides in animal tissues by thiobarbituric acid reaction. Anal. Biochem. 95:351-8.

Pellegrino, J, Lima-Costa, FF, Carlos, MA, Mello, RT, 1977: Experimental chemotherapy of schistosomiasis mansoni. XIII. Activity of praziquantel, an isoquinolinepyrazino derivative, on mice, hamsters and Cebus monkeys. Z. Parasitenkd. 52, 2:151-68.

Peters, AP, Warren, KS, 1969: A rapid method of infecting mice \& other laboratory animals with Schistosoma mansoni subcutaneous injection. J. Parasitol. 55:558-63.

Sakr, SA, 2007: Ameliorative Effect of ginger (Zingiber officinale) on Mancozeb fungicide induced liver injury in albino rats. Aust. J. Basi. Appl. Sci. 1, 4:650-6.

Schmidit, E, Schmidit, FW, 1981: Kline Enzyme Fiebel Schriftenreihe. Diagnostic Boehringer Mannheim. $3^{\text {rd }}$ ed.

Smolinski, AT, Pestka, JJ, 2005: Modulation of proinflammatory cytokine production in vitro and in vivo by the herbal Consistuents apigenin (chamomile), gineenoside $\mathrm{Rb} 1$ and parthenolide (fever few). Food Chem. Toxicol. 41:1381-90.

Suleiman, MI, Akarim, EI, Ibrahim, KE, Saad, AM, Mohammed, AE, et al, 2004: Antischistosomal effects of praziquantel, its alkaline 
hydrolysis and sun decomposed products on experimentally $S$. mansoni infected albino mice. (A) Efficacy assessment based on clinicopathological findings. J. Egypt. Soc. Parasitol. 34, 1: 131-42.

Tripathi, AK, Banerjee, BD, 2008: Protective effects of dietary ginger (Zingiber officinales

Rosc.) on lindane induced oxidative stress in rats. Phytother. Res. 22, 7:902-6.

Utzinger, J, Chollet, J, Tu, Z, Xiao, S, Tanner, M, 2002: Comparative study of the effects of artemether and artesunate on juvenile and adult Schistosoma mansoni in experimentally infected mice. Trans. R. Soc. Trop. Med. Hyg. 96, 3:31823.

\section{Explanation of figures}

Fig. 1: Effect of different drugs treatment on worm burden in different study groups.

Fig. 2: Oogram pattern in different study groups.

Fig. 3: Egg count per gram of liver \& intestinal tissue.
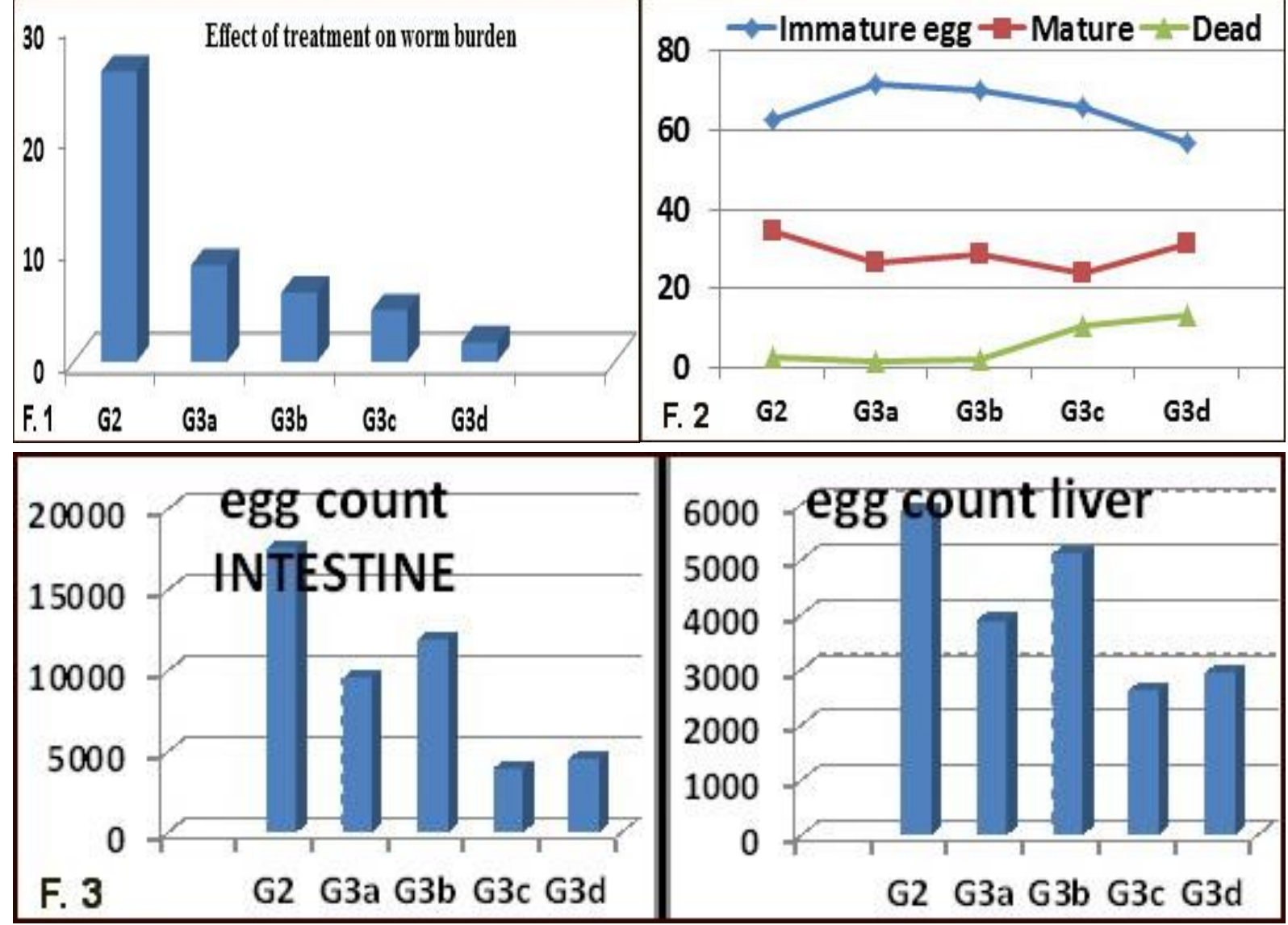